\title{
CONCEPT FOR A NEW OCEAN-MONITORING BUOY DESIGN
}

\author{
Brett Wilson
}

\author{
National Data Buoy Center \\ NSTL, MS 39529
}

\begin{abstract}
The National Data Buoy Center (NDBC) operates an extensive fleet of moored buoys in the Atlantic and Pacific Oceans off North America, off Hawaii; and in the Great Lakes. The buoys provide automated en. vironmental observations for use in weather analysis and forecasting. Low-power, electronic payloads on the buoys acquire, process, and transmit hourly data to shore via the Geostationary Operational Environmental Satellite (GOES) system. As the buoy array has grown, the number of observations has dramatically increased. At the same time, performance has improved, so that today the overall network data reliability exceeds 85 percent.

Recently, efforts at NDBC were aimed at reducing costs while maintaining performance standards. An example is the development of the Value Engineered Environmental Payload (VEEP), a highcapability system with an acquisition cost half that of its predecessor. Another example is the inexpensive 3-meter buoy hull, for which a broad range of capabilities has been demonstrated.

It is possible to conceive of another buoy design aimed at providing substantial operational savings through an extended deployment duration, perhaps of 4 to 6 years. This new buoy would be configured for ease of at-sea maintenance and will carry dual payloads for reliability. The engineering approach involved in the development of the new buoy concept is outlined in this paper.
\end{abstract}

\section{INTRODUCTION}

NDBC is continually seeking to improve the efficiency of its moored buoy program operations. This effort extends from the acquisition of equipment, through the conduct of effective quality assurance and logistics, to the implementation of an optimized at-sea maintenance strategy. The constraints imposed by technology, resources, and existing programs and equipment are all considered in this efficiencyimprovement activity. The concept outlined in this paper for a "NEWBUOY" (Figure 1) is one possible approach to increasing the overall cost effectiveness of moored buoy systems. Other strategies for the NDBC moored buoy network have been formulated as well, and the determination of the best approach has not been finalized. Consequently, the NEWBUOY may or may not represent the path NDBC will eventually take. However, as a buoy-design methodology, it does reflect the practice of NDBC at the design concept level.

\section{CONCEPT REQUIREMENTS AND SOLUTIONS}

\subsection{Operational Efficiency}

A moored buoy system consists of a data acquisition payload (including sensors), a power supply system, a buoy hull, and a mooring. Recently achieved cost reductions in NDBC payloads have diminished the relative returns that can be expected in acquisition costs for future payload designs. However, lower costs on future payloads will enable more cost-effective application of dual payloads for achieving higher reliability over a longer deployment time.

NDBC mooring design has improved so that a 6 -year life is now

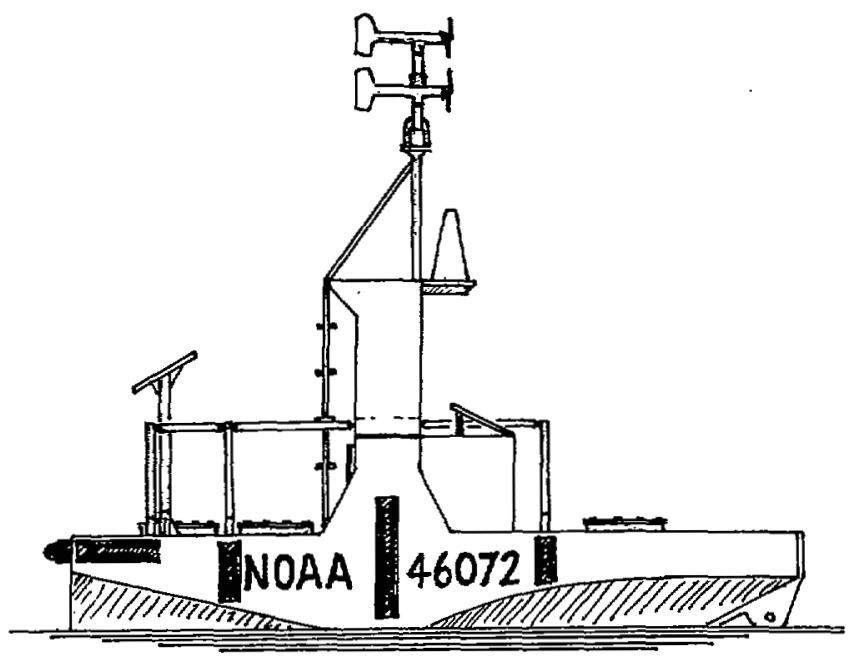

Figure 1. Outboard Profile - Aluminum NEWBUOY

standard. The characteristics of mooring materials (synthetic line and steel chain) make unlikely any dramatic extensions in mooring life or reductions in initial costs, even though a mooring may represent a large portion of the total system investment for a given buoy station.

The buoy hull is an item for potential cost savings. Although the choice of materials for structural use in the marine environment is fairly limited, substantial differences in fabrication and maintenance costs are possible. Typically, a trade-off will be necessary between an inexpensive but difficult to maintain material, such as steel, and an expensive but easily maintained material, such as aluminum. Cost reductions are most likely to result from decreasing the amount of material used. Scantlings for the range of hull sizes expected for NDBC buoys are based primarily on lateral plate loading rather than primary hull girder bending, and thus, will remain fairly constant between buoys. As a result, not only material cost, but also fabrication cost will vary in proportion to overall material weight. So, savings in hull costs for a given material, especially for aluminum or steel construction, may ensue from designing a smaller buoy. Of course, smaller buoys may be difficult, if not impossible, to service at sea. Fiber reinforced plastic may not follow the above trend for metals. The power supply system is an area for savings, both in the cost of batteries and also in the cost of installing the battery arrays. Reference 1 documented an analysis of solar and wave turbine power for NDBC buoys and concluded that solar power was economically attractive. Subsequently, NDBC has installed and operated numerous photovoltaic power systems on its operational moored buoys.

Overall, with regard to acquisition costs, the potential for reductions that can be amortized to represent operational savings is limited to the buoy hull, payload, and power system. In light of NDBC's historical improvements in this area, further acquisition cost reduc-

\section{U.S. Government work not protected by U.S. copyright}


tions can be expected to be marginal. Alternatively, maintenance and operations may contain areas amenable to substantial savings.

Operating costs can be lowered by increasing payload reliability, thereby decreasing the frequency of service visits, and by keeping the buoy on station longer than 2 years, perhaps for the entire 6-year nominal mooring life. This operational strategy will eliminate biennial buoy refurbishments. Leaving a buoy at sea for 6 years would require a system design with a great degree of at-sea serviceability. All payload, power system, and sensor suite components (Line Replaceable Units, (LRU's)), must be quickly, safely, and easily replaceable at sea.

In light of a 6-year retrieval period, the objective that the NEWBUOY be carried on the deck of a Coast Guard buoy tender, while desirable, becomes less pressing. In fact, the size of the buoy (deck area and superstructure) required for adequate at-sea working room may be too large for lifting onto a buoy tender. Thus, a valid argument can be forwarded that the NEWBUOY be capable of being towed at a reasonable speed. The NEWBUOY hull should be designed for loading on a "low-boy" trailer for interstate trucking. This would enable buoy refurbishment at NDBC (or other regional depot) and avoid the use of commercial shipyards for overhaul. Higher quality control of the refurbishment process along with a lower labor fee (due to reduced travel and per diem) justify the use of a hub facility for all overhaul and integration activities.

\subsection{Operational Reliability}

The reliability of NDBC payloads has increased as improved electronics and sensor systems have been thoroughly tested, evaluated, and incorporated into the buoy fleet. Nevertheless, reliability improvements are still possible and can be most effectively attained through additional payload redundancy. Physical limitations will likely prevent installation of complete dual payloads with all their sensors (e.g., a 4-anemometer buoy configuration is probably not possible).

Dual payload systems raise some questions regarding the operating configuration and the means of controlling the payload output. An example is the issue of whether to run both payloads at all times or to have the second start up upon failure of the first. Also, a key question is the issue of system control for shutdown and startup, and whether that control should reside on the buoy as an automatic feature or at NDBC, telemetered via GOES to a receiver on the buoy.

In addition to dual payloads, redundancy can be applied to power systems and data transmission to limited extents without excessive penalty. Use of Argos for position determination could be augmented inexpensively to provide a continuous or selectable backup data relay. Power system redundancy can be achieved with a combination of solar photovoltaic panels, limited primary batteries, secondary batteries, and possibly wave turbines.

\subsection{Sensor Compatibility.}

Meteorological sensors should be located at a nominal 5-meter height above the sea surface in keeping with the NDBC standard. These sensors should also be positioned such that the effects of buoy motions on sensor measurements and structural integrity are minimized. The ocean temperature sensor should be installed so that it is not affected by the solar heating of the hull. Finally, the natural frequencies of the hull in pitch and heave should occur outside the frequency band of greatest interest in wave measurement.

\subsection{Survivability}

The NEWBUOY must have adequate intact and damaged stability (including hull icing cases), acceptable motions in a severe seaway (i.e. resistance to pitch-poling and dynamic capsizing), and some protection against vandalism. In addition, the hull material must be com patible with the marine environment, (i.e., it must not be subject to excessive corrosion or abrasion).

\subsection{Lifespan and Acquisition Cost}

A present-value analysis taking into account the time-value of money is an accepted method of justifying expenditures over the lifespan of a project. Based on a 10\% cost of money, Reference 3, a present-value analysis of the savings in eliminating biennial refurbishments over one, two, and three mooring lives (i.e., 6, 12, and 18 years, respectively) yields amounts of $\$ 110 \mathrm{~K}, \$ 160 \mathrm{~K}$, and $\$ 200 \mathrm{~K}$ as the initial expenses that would result in break-even present value of costs. Buoy configurations that can be left at sea for a 6 -year period and have initial costs less than the above amounts will be economically attractive. Unless a major reduction in hull acquisition cost can be obtained via novel hull materials or fabrication techniques, the NEWBUOY should be designed for the longest reasonable lifespan (18 years or longer). The concept of a 6-year life hull, which would essentially be expendable on each deployment (not that it would selfdestruct at 6 years, but that it would be more cost-effective to replace than refurbish), may not be technically feasible.

\subsection{Growth Capability}

It is conceivable that sensors, in addition to the standard complement, will be installed on the NEWBUOY in support of either operational, research, or technology development missions. To accommodate these growth sensors, the payload must be capable of accepting additional inputs in either analog or digital (possibly preprocessed) form. The VEEP has a reasonable level of excess capacity in this regard. Otherwise, it is a matter or providing adequate area, volume, and displacement growth margins to accommodate new sensors and the increase if any, in the power supply. Potential-growth sensors may include humidity, permanent subsurface temperature lines, acoustic link receivers, expendable subsurface sensors, and further out, upper-air radiometric profilers.

\section{CONCEPT DESIGN}

\subsection{Payload}

A system schematic for the NEWBUOY payload, taking into account the factors described previously, is shown in Figure 2. From a reliability standpoint, the high component count is more than offset by the

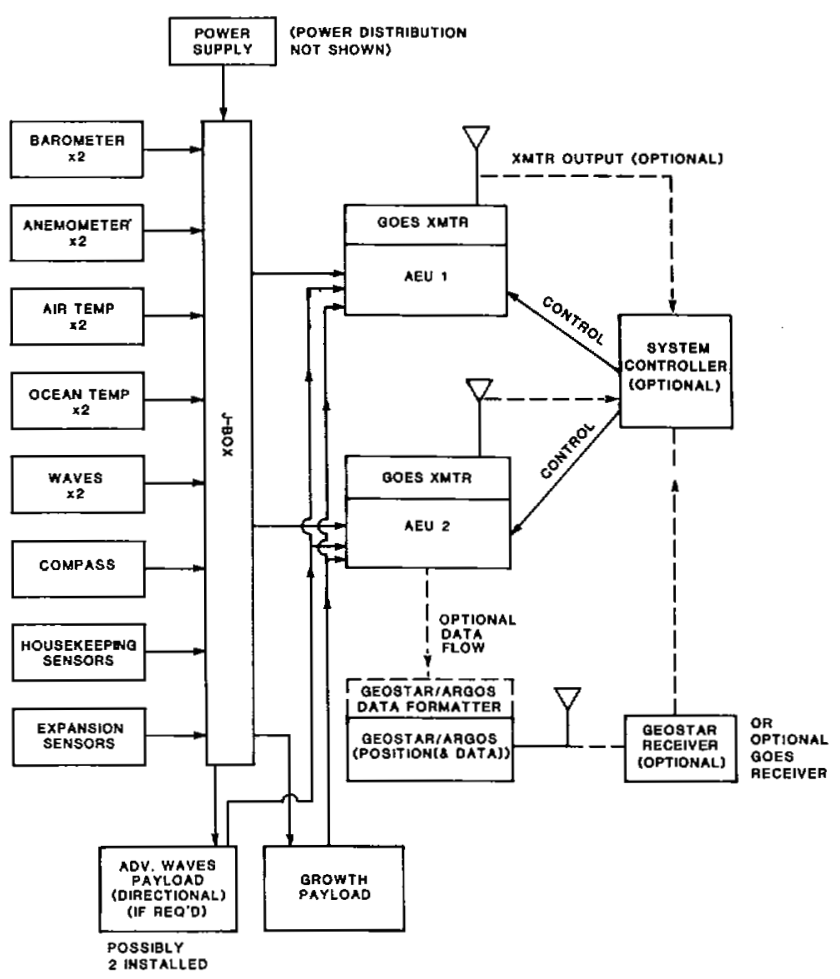

Figure 2. NEWBUOY Payload Schematic 
parellel-path duplication. Two separate Advanced Electronics Units (AEU) are installed with their own enclosures for redundancy and ease of maintenance. Each would have the capability to perform the same measurand processing (i.e., dual wind speed, gust, and direction barometric pressure; air temperature; sea surface temperature; and nondirectional waves). The AEU would be equipped with a nominal level of excess capability; however, major sensor growth would be accommodated through the addition of a dedicated AEU specifically adapted for that sensor. This "building block" philosophy enables the acquisition of a single payload in large quantities, resulting in costeffective procurement, logistics, and maintenance.

Both AEU's would be "on" through the entire deployment to avoid the difficulties associated with remote, unattended initiation and burn-in (which would be required if the system were designed so that the backup AEU were dormant until failure of the primary). The System Controller would disable a failed AEU on instruction received through a GOES receiver. This capability is not essential and may not be desired, but it is technically feasible and should be reasonably inexpensive.

The NEWBUOY power system would provide redundancy through solar panel arrays feeding secondary batteries. A limited amount of primary batteries would also be installed, and intended for replacement at sea at 1-or 2-year intervals.

Packaging of payload LRU's would be accomplished for ease of atsea testing, removal, and replacement. Tie-downs, sensor mounts, and cables would be quick-connect/disconnect. LRU size and weight would be limited to that which can conveniently be handled by one man in the marine environment. An LRU might consist of severa related payload items arranged within a single, easily detached/installed, watertight enclosure. This enclosure module would be designed to float or to accept an easily attached flotation device for safety in transporting from the repair vessel to the buoy, and vice versa. It is assumed that service visits would be conducted by directly plac ing technicians onto the buoy from the service vessel or ship's boat. The constraints imposed on buoy size will make it difficult to work below deck to perform a substantial swap-out of LRU's. Therefore, all LRU's would be located where they are easily accessible. Protection of LRU modules and related cable connections would be provided by a payload enclosure housing.

\subsection{Hulls}

A preliminary hull design effort was undertaken to meet the follow. ing design objectives:

- 6-year at-sea service. Primarily, this necessitates an arrangement in which LRUs were accessible and easily replaced by service personnel on the buoy. Liberal deck area was a corresponding objective.

- 18-year, or longer, lifespan requiring a hull adequate to resist the wear, abrasior, and corrosion anticipated over this lifespan. Initially, steel, aluminum, and glass-reinforced plastic (GRP) were considered. The GRP alternative was rejected due to insufficient abrasion resistance, low impact strength, and the difficulty of ensuring the integrity of secondary GRP bonds. For steel, corrosion is a considerably greater concern than for aluminum. Accordingly, anticorrosive protection and substantial corrosion allowances on the steel hull scantlings were incorporated into the design.

- Towing considerations led to the development of as fair a set of lines as possible within the limits imposed by other required hull characteristics. The underwater hull was also designed to provide directional stability for ease in tow.

- Constraints on transport over land via low-boy trailers were set as follows:

Length - 40-foot maximum

beam - 14-foot maximum

height - 10-foot maximum (based on a 3-foot-high low-boy and a 13-foot total vertical roadway clearance).

Note that the beam must include space for fenders approximately 6 inches wide on each side of the buoy. Thus, the hull beam limit is 13 feet, maximum.

- Survivability dictated adequate intact and damaged stability. At this preliminary level, these were translated into adequate initial stability, liberal freeboard (for both reserve buoyancy and range of the stability curve), and compartmentation. However, the amount of compartmentation attainable without an excessively expensive hull structure is probably not sufficient for some likely damage cases. Therefore, a method for decreasing the permeability of the compartments was required while still allowing access to compartment interiors.

- Minimizing acquisition cost led to a secondary goal of obtaining a simple structural configuration within the bounds of the major hull parameters.

- As long as the beam limit was not violated, the designs would attempt to avoid the use of ballast. This constraint was reinforced by the buoy at-sea service considerations for a large deck working area.

- Anemometers were to be located at the 5-meter level in accordance with the NDBC standard for NOMAD and 3-meter buoys. A location amidships was desired to minimize pitch-induced accelerations, which are proportional to the arm from the buoy center of gravity. Hull characteristics were selected so as to achieve natural periods lower than the range of wave periods of interest, i.e., less than 4 seconds (Table 1). Surface-following characteristics were assumed to correspond with a high waterplane area-to-displacement ratio (Table 1).

- Finally, the buoy arrangement should contain some growth margin for future payload requirements.

Two point designs, one steel and the other aluminum, were developed to the stage where estimating algorithms for hull characteristics, etc., were determined to produce realistic results. Weights for payload components were estimated from NDBC experience. Hull structural weights and centers were estimated via relationships in terms of Cubic Number based on comprehensive data (Reference 4) for small commercial working vessels. The aluminum structural weight relationship was validated against the VE NOMAD.

To reduce permeability for damage stability purposes, closed-cell foam blocks inside of net-type bags were assumed to fill a substantial portion of each compartment. In this way, the foam would be easily removed by hand through the hatches enabling inspection of interior compartment structures at the 6-year retrieval.

Hullform estimating relationships based on Reference 4 were employed to make initial determinations of satisfactory hull characteristics, particularly stability. Reserve buoyancy and freeboard criteria were also selected as shown in Table 1.

Table 1. Hull Design Constraints \& Objectives

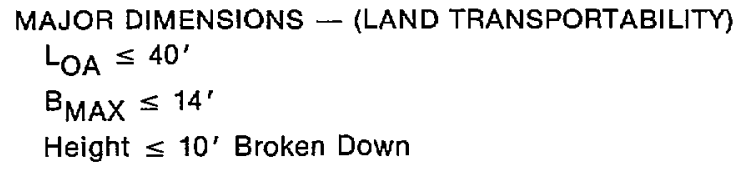

$$
\begin{aligned}
& \text { MOTIONS } \\
& \mathrm{T}_{\text {Pitch }}<3 s \rightarrow \mathrm{T}_{\mathrm{P}}=2 \pi \sqrt{\mathrm{L}^{2} / 435 \mathrm{GM}_{\mathrm{L}}} \\
& \text { Letting } G M_{L}=A \cdot L \text {, Solving } A=L 99.17 \\
& \text { Then } \mathrm{GM}_{\mathrm{L}} \geq \mathrm{L}^{2} / 99.17 \\
& T_{\text {Roll }}<3 s \quad T_{R}=2 \pi \sqrt{\mathrm{K}^{2} / \mathrm{gGM}_{T}} \text { where } \mathrm{K}=0.39 \mathrm{~B} \\
& \text { Letting } \mathrm{GM}_{\mathrm{T}}=\mathrm{C} \cdot \mathrm{B} \text {, Solving } \mathrm{C}=\mathrm{B} / 48.3 \\
& \text { Then } \mathrm{GM}_{\mathrm{T}} \geq \mathrm{B}^{2} / 48.3 \\
& T_{\text {Heave }}<3 s \quad T_{H}=2 \pi \sqrt{\nabla(1+\mathrm{Ca}) / g A W} \\
& \mathrm{Ca}=1.25 \text { Typ., } \nabla=C_{B} \text { LBT, } A W=C_{W} \text { LB } \\
& \text { Solving for } \mathrm{C}_{B^{\prime}} / \mathrm{C}_{W} \sim .5=\mathrm{C}_{V P} \\
& \text { Then } \mathrm{T} \leq 6.48^{\prime} \text { Or } \mathrm{T} \bullet \mathrm{C}_{\mathrm{VP}} \leq 3.24 \text { for any } \mathrm{C}_{\mathrm{VP}}
\end{aligned}
$$

HIGH AWPID RATIO

Corresponds to Low $\mathrm{T} \cdot \mathrm{C}_{\mathrm{VP}}$ Product

3-M Discus -0.74

NOMAD -1.92

10-M Discus - 2.01

FREEBOARD: $\geq 2^{\prime}$

RESERVE BUOYANCY: $\geq 50 \% \nabla$ 
Based on the above relationships, numerical designs were performed until all criteria were met. Typically, transverse stability and the associated natural period in roll were the critical elements. Weight and KG margins of 1,000 pounds and 0.5 foot were incorporated into the weight estimate to account for uncertainty and growth in the design and fabrication phases.

Point Designs - Sectional area curves for the steel and aluminum designs were developed based on the prismatic coefficients in the numerical designs and on an effort to obtain an LCB forward of amidships for directional stability purposes. The steel hull is much fuller than the aluminum hull. This is primarily due to structural weight with the liberal corrosion allowance on scantlings.

Based on the sectional area curves, line drawings were developed. The steel buoy lines are shown in Figure 3. All surfaces are developable (i.e., able to be formed of conical or cylindrical sections with one axis of curvature). The objective was to achieve a hull shape that could be built easily and inexpensively; thus, the single chine, planar sides and flat transom. The halfbreadth at the deck is 0.5 foot greater than at the waterline for purposes of protection. Similarly, the aft edge of the keel is sloped forward as it approaches the baseline.

The steel hull lines indicate that buttock flow will predominate both fore and aft. Directional stability was assessed based on the method of Reference 5 for estimating the controls-fixed directional stability index. The method showed that the buoy should be stable in tow, alleviating towing control difficulties and reducing resistance as well.
A resistance estimate for the steel hull was performed partially on Reference 6. At 10 knots, the calm-water, clean-bottom resistance was computed to be 3200 pounds.

The much finer aluminum hull lines are given in Figure 4. Maintaining a developable surface hull for the low prismatic coefficient led to considerable rake of stem and cutaway at both bow and stern. As a result, the aluminum buoy is longer overall (same length on waterline) than the steel buoy. Extrapolations for computing the drag of the aluminum buoy were excessive, so a resistance estimate was not done. Since the aluminum hull has less wetted surface and a lower displacement than the steel hull, its resistance will also be somewhat less.

A preliminary structural arrangement for the steel hull is shown in Figure 5. The structure is transversely framed, since, with the short hull length, longitudinal bending stresses will be low. A convenient frame spacing of 30 inches was selected to reduce fabrication costs. Scantlings are substantially greater than those required by the American Bureau of Shipping (ABS) Rules (Reference 7). Shell and deck scantlings were also checked via first principles for lateral plate loading. The extra shell, keel, bulkhead, and deck thicknesses (greater by 0.25 inch than ABS required in all cases ) are corrosion allowances. This liberal allowance is essential as insurance against corrosion over the life of the buoy (nominally 18 years). The entire interior and exterior of the hull would be coated with a suitable anticorrosive paint that would be renewed at the six-year overhaul periods. Zinc sacrificial anodes would also be installed on the hull. An estimate of the hull
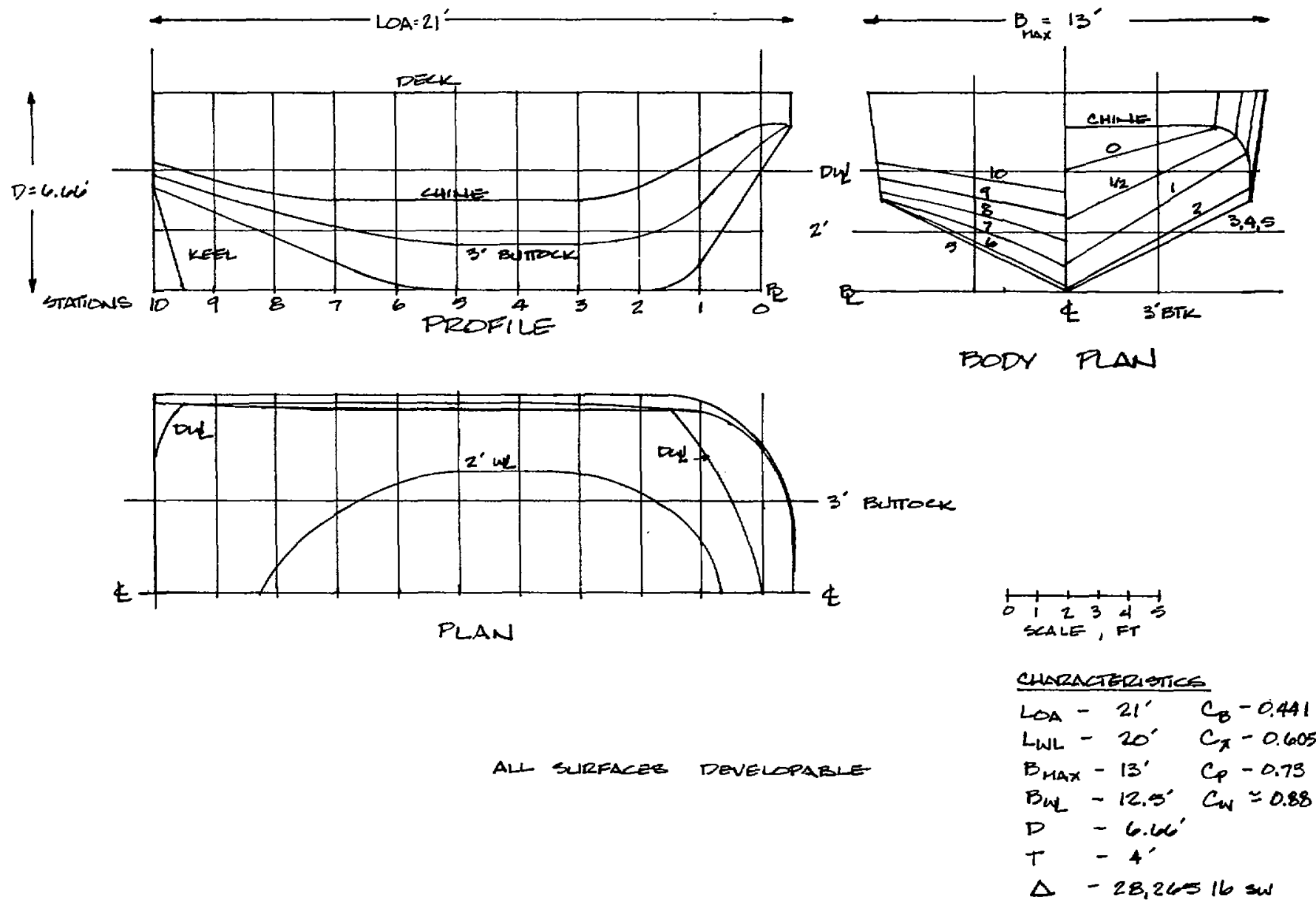

Figure 3. Steel Hull Lines 

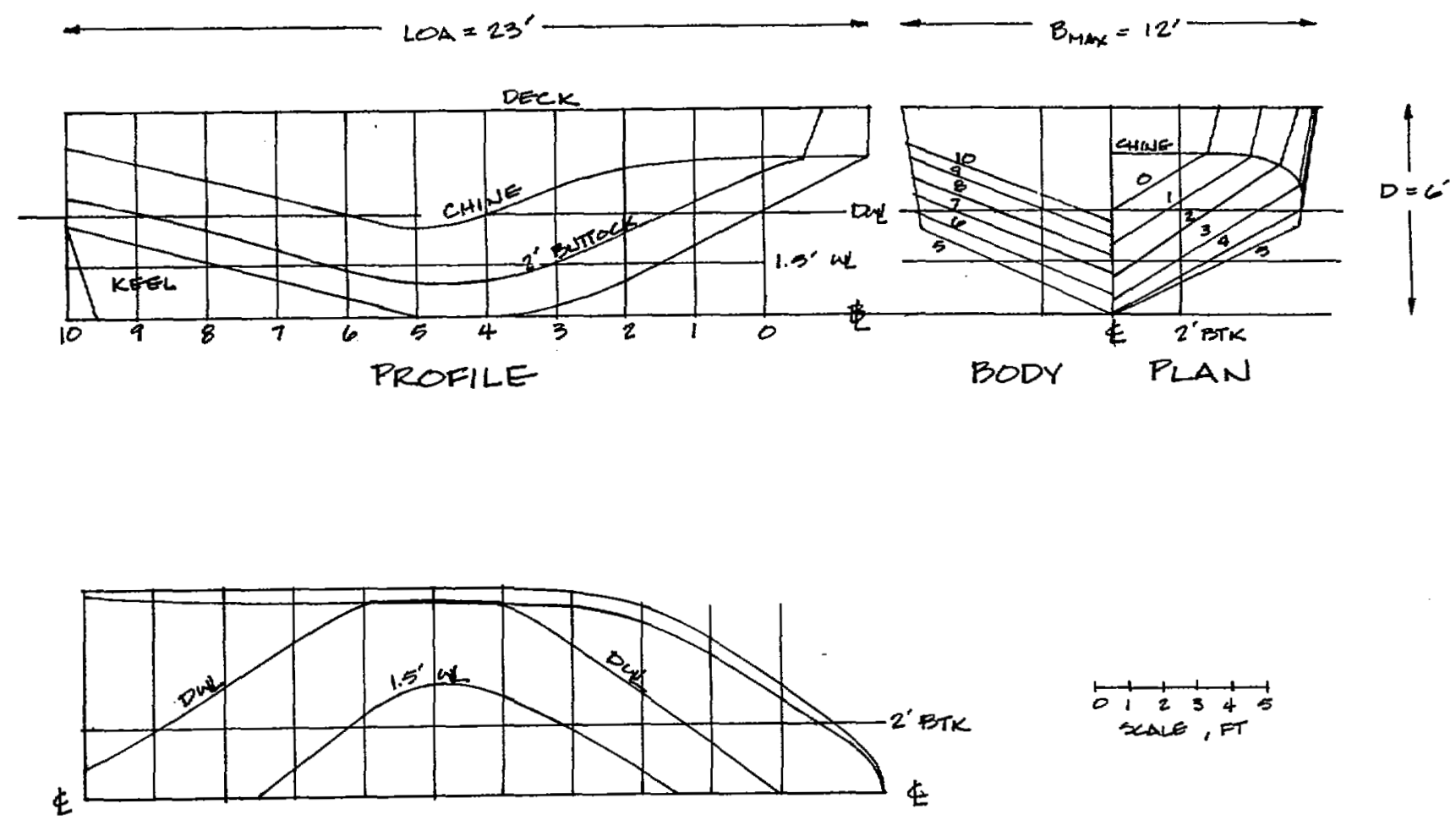

PLAN

\begin{tabular}{|c|c|c|}
\hline \multicolumn{2}{|c|}{ CHARATERSTLS CS -0.251} & $C_{B}-0.251$ \\
\hline Lute & $-20^{\prime}$ & $c_{x}-0.58$ \\
\hline Bmax & $-12^{\prime}$ & $c_{p}=0.496$ \\
\hline Bud & $-11^{\prime}$ & $c_{w}-0,642$ \\
\hline$D$ & $-\infty^{\prime}$ & \\
\hline$T$ & $-3^{\prime}$ & \\
\hline$\Delta$ & -10, & \\
\hline
\end{tabular}

Figure 4. Aluminum Hull lines

structural weight yielded a total of 24,900 pounds.

The struture for the aluminum buoy is similar to Figure 5 , in general. The hull material was assumed to be $\mathbf{5 0 8 6}$ marine alloy aluminum. Scantlings were determined from lateral plate loading for the shell and deck using NDBC criteria from the VE.NOMAD design (which were taken from the 10-meter discus designs and are very conservative). Other scantlings were estimated. Based on these, the weight of the aluminum buoy was roughly calculated as 7,200 pounds. The structural plans for both buoys provided weights close to the preliminary numerically derived estimates.

General arrangement plans were drawn for both buoys, although only the aluminum buoy plan is shown (Figure 6). The following discussion centers around the aluminum buoy - all essentials are the same for the steel buoy.

First, the buoy was configured to be carried by low-boy trailer. As a result, the mast and all railings would be dismantled in shipment and reconnected prior to deployment. Hull side fenders are not shown in Figure 6, but would bring the maximum breadth to near the 14-foot limit.

Below decks, four compartments in the steel hull, and five in the aluminum, provide adequate protection against damage. Longitudinal bulkheads were not considered in order to prevent asymmetrical flooding and minimize structural weight. Each compartment (except for the bow void on the aluminum buoy) will be filled with bags con taining blocks of closed-cell foam to reduce compartment permeability. The bags would be dropped by hand through the hatches and arranged to fill up the compartment. Each bag might contain 4 to 8 cubic feet of foam. In this manner, the hull would survive even if two or three compartment's were violated as long as the damage did not leave extremely large, gaping holes in the shell, thereby allowing the foam bags to escape.

The entire payload would be installed above deck in a payload compartment with an aft-facing hatch or watertight door. The payload would be comprised of several watertight, possibly floatable modules that could be installed inside the deck compartment. Each module would be limited in size and weight ( 2 feet $\times 2$ feet $\times 3$ feet and 50 pounds, approximately) so that it could be easily handled on deck. These modules would be taken on and off the buoy via the stern. The payload compartment interior would have slots and quick disconnect fittings to accommodate the modules.

Cabling would be arranged within the payload compartment to provide easy access to connectors. Cabling to exterior sensors would be configured with an easy disconnect to or through a watertight stuffing tube into the payload compartment. One possibility is a pipe serving as a cable way to the sensors, antennae, and solar systems above deck. Note that a cable run would also need to be made to a sea surface temperature sensor. This sensor would be contained in a detachable probe mounted in a through-hull, small-diameter, sensor well tube.

Two solar photovoltaic arrays are shown. Exact sizes and layouts would require further definition. A small quantity of batteries is critical to the entire NEWBUOY concept in which all replaceable items are carried above deck. It is assumed that these batteries would be replaced at 1 - to 2 -year intervals during at-sea service visits.

Access to the above-deck sensors would be by ladder to a working platform 8 feet above deck. All antennae, the $0 \& 1$ light, and the two 
PROFILE C $E$
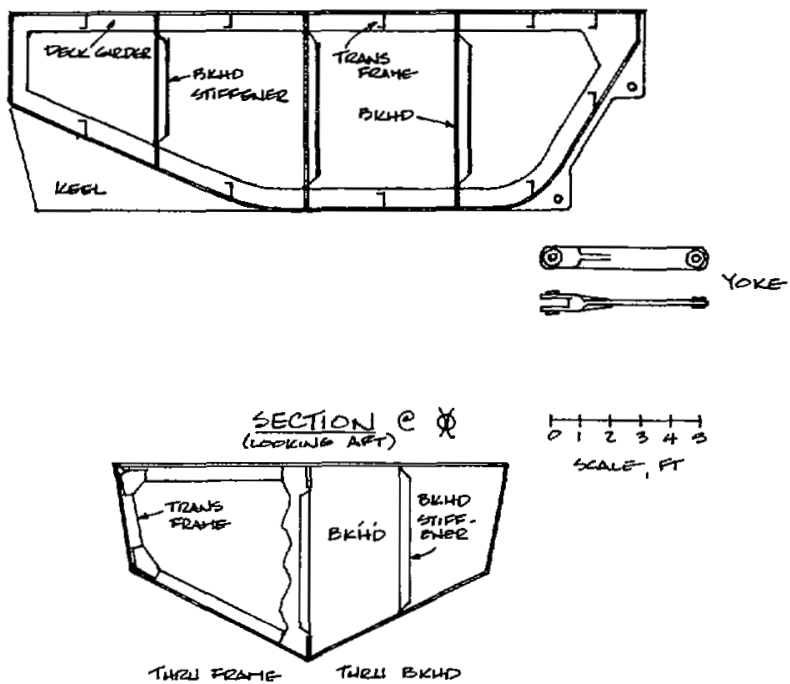

SCANTIUNGS

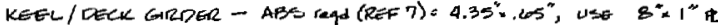

SHELL - ABS read bottom $=.215^{\prime \prime}$, USE $t=1 / 2$ " BOTTOM SADES, THe

FRamiala - SPACinte - ABS suppeted $=20.2 "$, we bo" SM ragd $=2.21 \mathrm{in}^{3}-90$ to $4 \mathrm{in}^{3}-$ we $5 \times 3^{\circ} \times 4^{4} \mathrm{~T}$

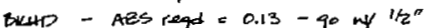

Figure 5. Steel Hull Structural Arrangement
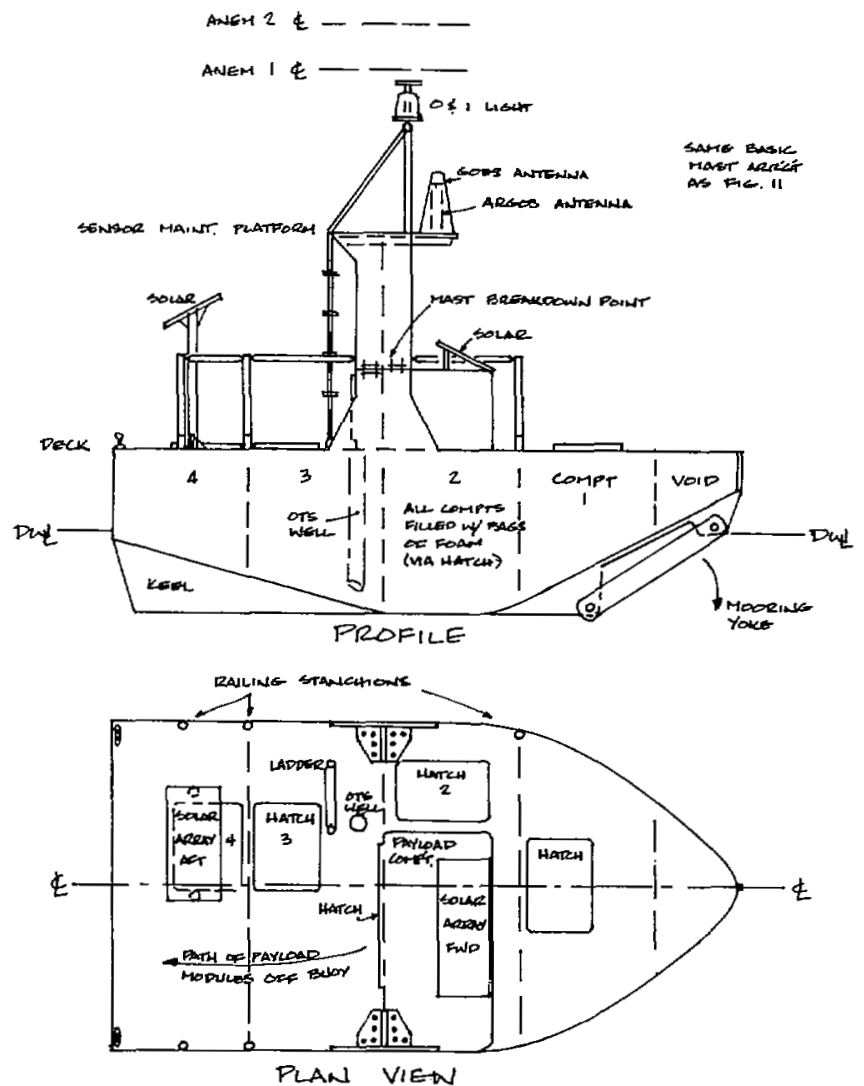

Figure 6. Aluminum Hull General Arrangement anemometers are located on the mast. The service technician would strap a harness to the transverse safety railing on the mast after climbing up. The presence of a service technician on the mast along with another technician and 500 pounds of equipment above deck has minimal effect on transverse stability for the steel hull and a small, but acceptable, effect for the aluminum hull.

The mooring yoke is a single bar attached to the forward keel. During tow, the yoke would be hinged up and connected to the bow by a pin (ostensibly on the towing shackle). A preliminary bending/ten sion calculation for a mooring load equal to twice the displacement and a 30-degree roll showed that the yoke design is feasible. Details on the pin hinge and yoke will require further effort. Longitudinal hydrostatics in moored conditions also need to be analyzed in greater detail.

Hull Costs - Fabrication costs per pound for steel and aluminum are approximately $\$ 1$ and $\$ 8$ to $\$ 11.50$, respectively, based on recent quotes (References 8 and 9 ). Using $\$ 1.50$ plus 40 percent for coatings for steel and $\$ 11.50$ for aluminum, the corresponding costs for the NEWBUOY are:

Steel hull $-\$ 52,500$

Aluminum hull - $\$ 83,500$

It is possible that the steel hull cost estimate is unrealistically high. Nevertheless, unless it were 20 percent less than above, the longrange benefits of aluminum might outweigh the cost advantage of steel. An additional advantage of aluminum is the easier calibration of aluminum hulls for directional wave measurements.

\section{REFERENCES}

1. A Feasibility Study of Alternative Power Systems for NDBC Moored Buoys, C. Bond and W. B. Wilson, Computer Sciences Corp., for NDBC, August, 1983.

2. Memorandum from W/DB to W, Subject: MMS Pacific Outer Continental Shelf Data Buoy Support, January 4, 1985.

3. de Neufville, R. and J. Stafford, Systems Analysis for Engineers and Managers, McGraw-Hill, 1971.

4. Wilson, W. B. Fishing Vessel Design Curves, International Conference on Design, Construction, and Operation of Commercial Fishing Vessels, May, 1985.

5. Wilson, W. B., The Effect of Variations in Major Hull Parameters of Fishing Vessels Upon Directional Stability, International Conference on Fishing Vessels, May 1985.

6. Ridgely-Nevitt, Cedric, The Resistance of a High DisplacementLength Ratio Trawler Series, Transactions, Society of Naval Architects and Marine Engineers, 1967.

7. Rules for Building and Classing Steel Vessels Under 61 Meters in Length, American Bureau of Shipping, 1973.

8. Telephone conversation between Gulf Coast Fabrication and W. B. Wilson, NDBC, May 1986

9. W. B. Wilson, NDBC Price, Cost, and Operational Data Study, June 7,1984 